\title{
Performance of Bidirectional Converter Based On Grid Application
}

\author{
D. Vidhyalakshmi, K. Balaji \\ Department of Electrical and Electronics Engineering \\ St. Peters Institute of Higher Education and Research, Avadi, Chennai 600054, India
}

\begin{abstract}
Article Info
Article history:

Received Jul 23, 2018

Revised Sep 2, 2018

Accepted Sep 19, 2018

ABSTRACT

A transformer less bidirectional inverter fed grid-connected system has implemented and function as both forward and reverse power flow by battery and photovoltaic system. In dc distributed system has utilized the renewable energy such as PV, wind, battery and fuel system. In conventional method the dc bus regulation by using the one line cycle regulation method and one-sixth line cycle regulation. In proposed method utilize both converter and inverter operates bidirectional direction and utilize both solar and PV source. The solar

Keywords:

Battery

BidirectionalConverter

Photovoltaic

Proportional Integral Controller

Model Predictive control energy had less cost, pollution less energy generation and fed into the bidirectional converter. The PI-based control method is used to operate both forward and reverse direction. The model predictive control method is used in the bidirectional inverter for control the current and voltage of the gridconnected system. The power flow control in the distribution system by the constant power loads such as dc/dc converter because conduct the negative dynamic impedance. The three-phase bidirectional inverter is designed and implemented in MATLAB/Simulink environment.
\end{abstract}

Copyright $(2018$ Institute of Advanced Engineering and Science. All rights reserved.

\section{Corresponding Author:}

D. Vidhyalakshmi,

Research Scholar, Department of Electrical and Electronics Engineering,

St. Peters Institute of Higher Education and Research,

Chennai-60005, India.

Email: vidhyaphd05@gmail.com,kbalaji26@gmail.com

\section{INTRODUCTION}

In recent days the utilization of power electronic converter is increasing, and the bidirectional converter has more attractive. The bidirectional inverter used in medium and high power application. The galvanic isolation based transformer has more attractive and utilizes the pulse width modulation for regulating the dc link current. The phase shift angle in between primary and secondary control is used to maintain the power of the bidirectional inverter [1-2].

\subsection{Background}

The three-phase bidirectional inverter is a direct connection between the ac-ac converters and removes the utilization of dc link capacitor and enhances the current capability at dc side. The inverter has the high number of switches and uses transformer, and the output is fed into the ac-ac converter at low-frequency inductance for regulating the power flow [3-4]. The transformer less photovoltaic has high-frequency leg method function has both continuous and discontinuous current mode and having more reliability. The high switching frequency has to decrease the ripple in inductor and utilization of passive device is less [5].

\subsection{Problem}

The single stage power conversion for battery storage application and designed by multiple bidirectional converters connected in cascade. The power flow of the battery is regulated without using the 
current sensor [6]. The dc bus voltage control in three-phase inverter fed distribution system utilize the one cycle regulation and one-sixth line cycle regulation method. The boost converter is used, and it is unidirectional, and the inverter is bidirectional and fed into the grid system [7-8]. The dc bus has used in various application such as electric vehicle, air conditioner etc. The input photovoltaic and grid-based converter system is utilized for improving the voltage regulation [9]. The transformer-based bidirectional converter is connected in single phase inverter fed grid system. The single stage bidirectional converter with low input voltage utilizes the battery, and single control method is used to increase the efficiency [10-12]. The bidirectional converter has to utilize for saving the power to battery and can utilized for back up source. The backup converter used as a bidirectional converter for storing the electricity from the fuel cell [13-14].

\subsection{Objective}

a) In proposed bidirectional inverter has transfer the power from solar to grid and also transfers the power from grid to battery. The PV is not present the battery is used has a source and power fed into grid system.

b) The model predictive control technique has used in the inverter and PI controller has used in bidirectional converter for regulating the dc voltage and also improve the voltage gain.

\section{PROPOSED METHOD}

A bidirectional dc-dc inverter fed grid connected system is used for power transfer in both forward and reverse direction instead of two unidirectional converters and also to regulate the power flow. The battery is used for storing the reverse power from the grid and utilizes in electric vehicle application as well as act as the source when PV is not present. The proposed method has to reduce the current ripple in battery side. The PV fed grid-connected inverter has to decrease the total harmonic distortion across the load current and also improve the power factor correction. The PI control is used in the bidirectional converter for regulating the dc link voltage. The photovoltaic and battery based power generation is fed into bidirectional converter connected in a grid system.

\subsection{Implementation Pre-processing Steps \\ 2.1.1 Photovoltaic System}

The photovoltaic system has an important in distributed power generation. PV system consists of a number of solar cells these are connected in series for generating electrical power with high potential. The photons of light fall on the semiconductor material and the PN junction absorbs the radiation and forms the electron-hole pair causes the electrons flow in the material. The proposed solar power generation has nonlinear power can change with the environmental condition, less maintenance and cost-effective. The voltage produced from the PV cell depends on the semiconductor used and also varying temperature, insolation etc. [15]. Thus the light energy is converted to electrical energy. The two diode PV module is shown in Figure 1.

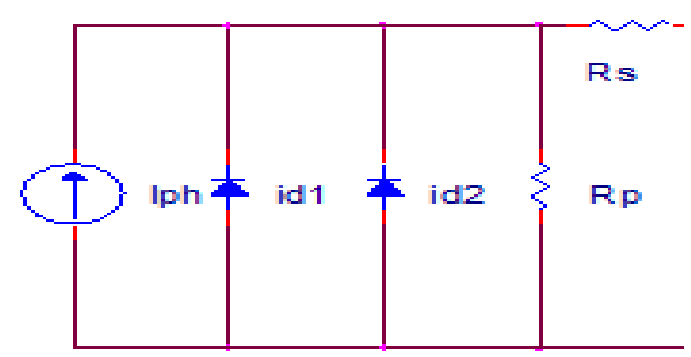

Figure 1. Photovoltaic cell

Based on two diode models, the non-ideal PV array output current can be expressed as,

$$
I_{\text {output }}=I_{\text {Photo }}-I_{\text {Diodel }}-I_{\text {Diode2 }}-I_{\text {shunt }}
$$

By using physics characteristic of $\mathrm{p}-\mathrm{n}$ junctions, a PV array could be designed by a DC source in parallel with two diodes and the current is acquiring away from due to the reason of diffusion and recombination of charge 
mechanisms. The above output current equation is consists of the light generated photo current, shunt current and diode action respectively [16-18]. This all corresponding equation is given below,

$$
\begin{aligned}
& I_{\text {Photo }}=I_{\text {ShrtCrt }}+K_{I}\left(T_{\text {Cell }}-T_{\text {reference }}\right) G \\
& I_{\text {output }}=N_{P} I_{\text {Photo }}-N_{P} I_{01}\left[\exp \left(\frac{V+I R_{S}\left(\frac{N_{S}}{N_{P}}\right)}{N_{S} \alpha_{1} V_{T}}\right)-1\right]-N_{P} I_{02}\left[\exp \left(\frac{V+R_{S}\left(\frac{N_{S}}{N_{P}}\right)}{N_{S} \alpha_{2} V_{T}}\right)-1\right]-\frac{V+I R_{S}\left(\frac{N_{S}}{N_{P}}\right)}{R_{P}\left(\frac{N_{S}}{N_{P}}\right)}
\end{aligned}
$$

\subsubsection{Bidirectional Converter}

The proposed bidirectional converter has to minimize the amount of switching device and reduce the THD. In order to improve the power factor by two-switch, the single inductor based buck-boost converter is used. The bidirectional DC-AC inverter mainly used to power balance the circuit. In bidirectional converters are used in many applications such as hybrid electric vehicles, distribution systems, electric aircrafts and uninterruptable power supplies. The bidirectional converter has two switches. One switch is used for forwarding direction and other for reverse direction power flow. The bidirectional converter has used to transfer the power from source to grid and also grid to the source by using the switch in series with the battery, and another switch is connected in series between the photovoltaic and bidirectional converter. The proposed circuit diagram is shown in Figure 2.

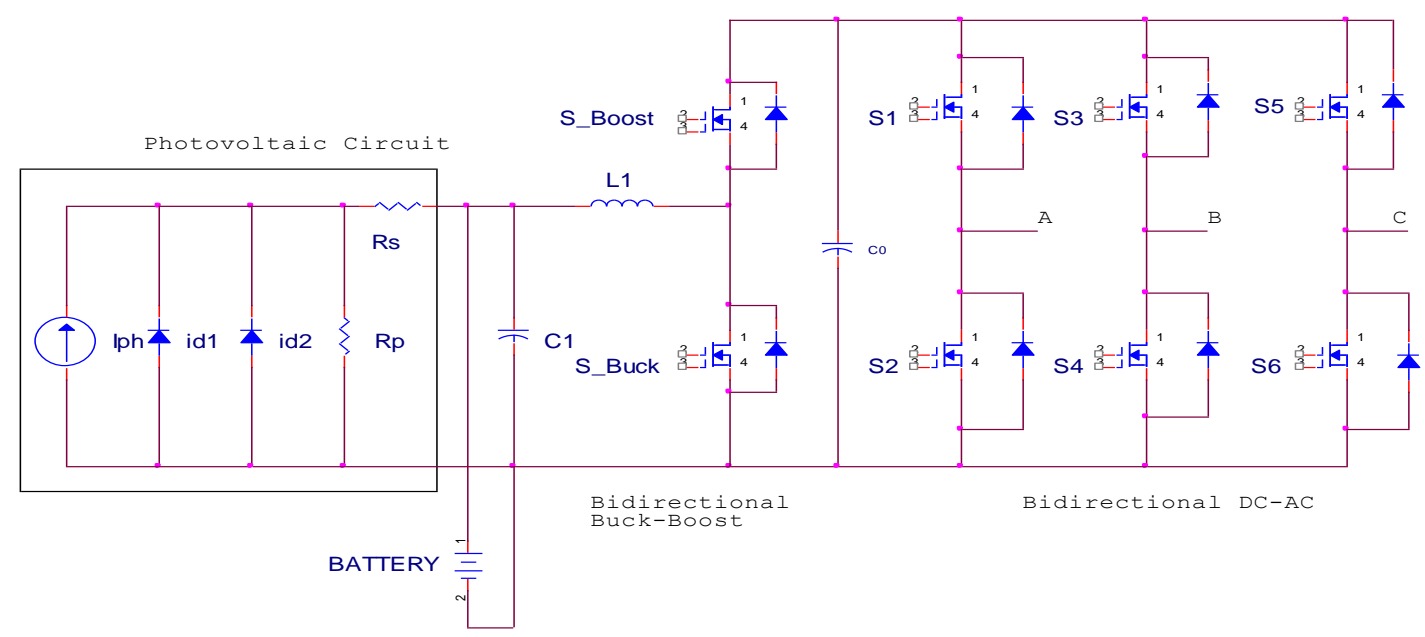

Figure 2. Proposed Circuit diagram of bidirectional converter fed grid connected system

In the bidirectional converter, the PV input is fed to the grid-connected system the switch across the battery is off. When the battery is used as the source, the switch will be on, and it will conduct both forward as well as reverse direction power flow.

\subsubsection{Model Predictive Control}

The model predictive control method is used in a bidirectional inverter to control the current and voltage. The input of the control is current and then processed to generate the pulse of the inverter. The model predictive control (MPC) has been applied for the control of power converters due to its several advantages, like a fast dynamic response, easy inclusion of nonlinearities and constraints of the system, and the flexibility to include other system requirements in the controller. MPC considers a model of the system in order to predict the future behaviour of the system over a horizon in time. The proposed control method is used to calculate the direct and quadrature axis current. This controller generates the voltage reference vector and fed to the simple boost control technique for regulating the power flow and has enhanced the system efficiency. The direct and quadrature axis voltage is calculated by using the proposed controller. The reference grid current is given in Equation 4 and 5. 


$$
\begin{aligned}
& i_{\text {dref }}=a^{*} i_{d}+b^{*} v_{d} \\
& i_{\text {qref }}=a^{*} i_{q}+b^{*} v_{q}
\end{aligned}
$$

The a and $\mathrm{b}$ value is given in Equation 6 and 7 . The $v_{d}$ and $v_{q}$ is given by the sinusoidal waveform.

$$
a=e^{-\frac{R_{L} T_{S}}{L_{L}}}
$$

$$
b=\frac{\left(1-e^{-\frac{R_{L} T_{S}}{L_{L}}}\right)}{R_{L}}
$$

The output of the proposed model predictive control is given in Equation 8 and 9.

$$
\begin{gathered}
V_{\text {dout }}=\frac{i_{\text {dref }}-a i_{d}}{b} \\
V_{\text {qout }}=\frac{i_{\text {qref }}-a i_{q}}{b}
\end{gathered}
$$

The output of the proposed controller is fed to the dq to abc transformation. The simple boost PWM control method is used to produce the pulse of the bidirectional inverter.

\subsection{Modes of Operation}

The proposed bidirectional based converter fed grid-connected system has to operate in various modes. The operation of photovoltaic fed bidirectional converter fed grid.

In mode 1 the supply of the proposed circuit is photovoltaic and fed into the bidirectional converter in grid connected system. The switch S1 turned off, and S2 is switched on, the inductor charges and current flows in a forward direction from PV to load through the S2 and bidirectional inverter. Figure 3(a) shows the PV based forward direction and fed into the load.

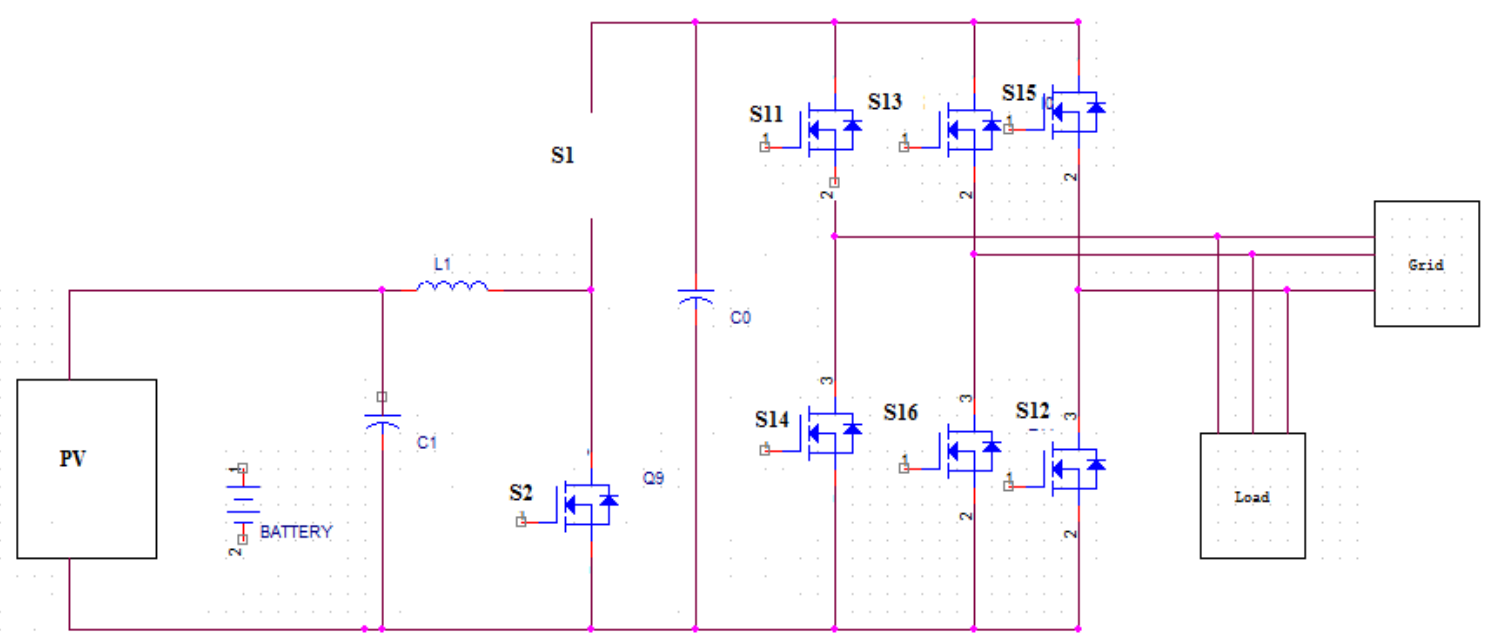

Figure 3(a). Power Flow from PV to Grid 
In Mode 2 the switch S2 is turned on, and S1 off the power flows from the battery to grid through the bidirectional inverter. The PV is disconnected from the proposed circuit. The battery is used as the source of the proposed network, and it is discharging. Figure 3(b) shows the power flow from the battery to the grid.

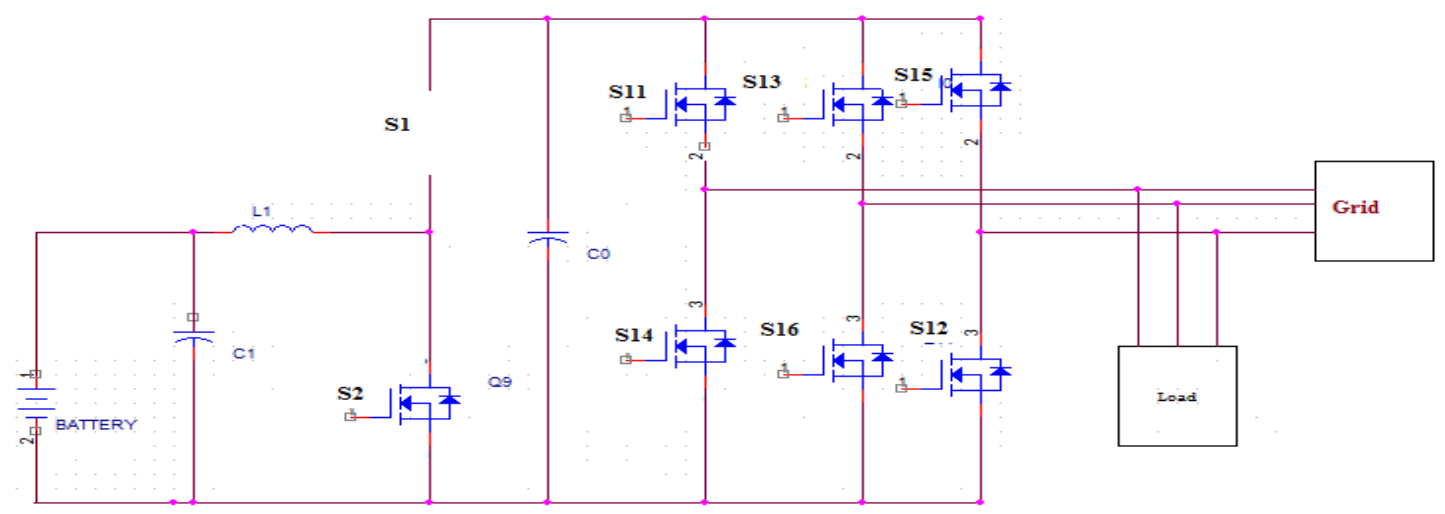

Figure 3(b). Power Flow from Battery to Grid

In Mode 3 the PV is disconnected from the bidirectional circuit. The grid is used as the supply, and bidirectional inverter function has a reverse direction. The current flows from grid to battery. Thus the battery was charging and used for external application. In reverse direction, the bidirectional inverter worked as rectifier because of input from grid supply and transferred to the battery. The pulse of the bidirectional inverter is zero when the inverter performs rectifier. The dc is converted to a bidirectional converter and stored in the battery. Thus the battery charging during this mode. Figure 3(c) shows the power flow from the grid to the battery.

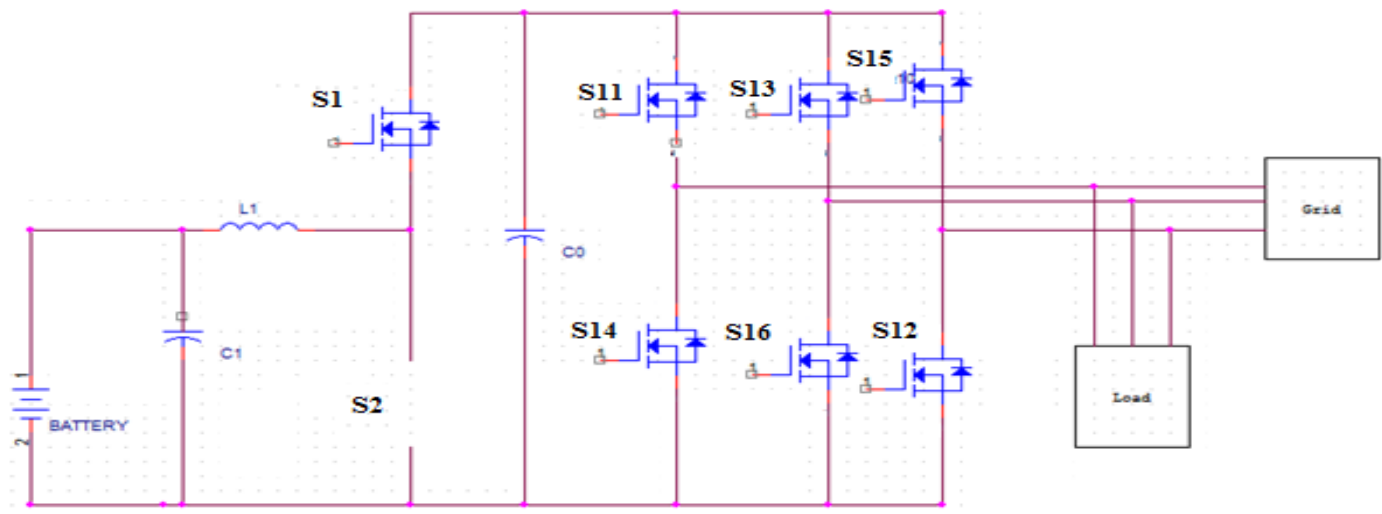

Figure 3(c). Power Flow from Grid to Battery

\section{Simulation Results}

The proposed renewable energy based bidirectional inverter fed grid-connected system configuration is implemented, and results are verified in MATLAB/SIMULINK. The power flow control of photovoltaic generation based on bidirectional inverter fed grid application is analyzed and verified with results of PI and mode predictive control techniques under nonlinear load condition. The PV output voltage waveform is shown in Figure 4. The PV output current waveform is shown in Figure 5.

Figure 6 shows the state of charge in the battery system. The time $0-1$ the photovoltaic is used as source and bidirectional converter function as the forward direction. The time 1-1.4 battery act as a source and the bidirectional converter has worked as the forward direction. The time 1.14-2.5 the grid act as a source and bidirectional converter function has reverse power flow direction. In forwarding direction, the battery discharges the power and supply to bidirectional inverter fed load system. In reverse direction battery charging. The DC link voltage waveform of the bidirectional converter is shown in Figure 7. The bidirectional inverter 
output voltage waveform is shown in Figure 8 . The bidirectional inverter output current waveform is shown in Figure 9. The total harmonic distortion is shown in Figure 10.

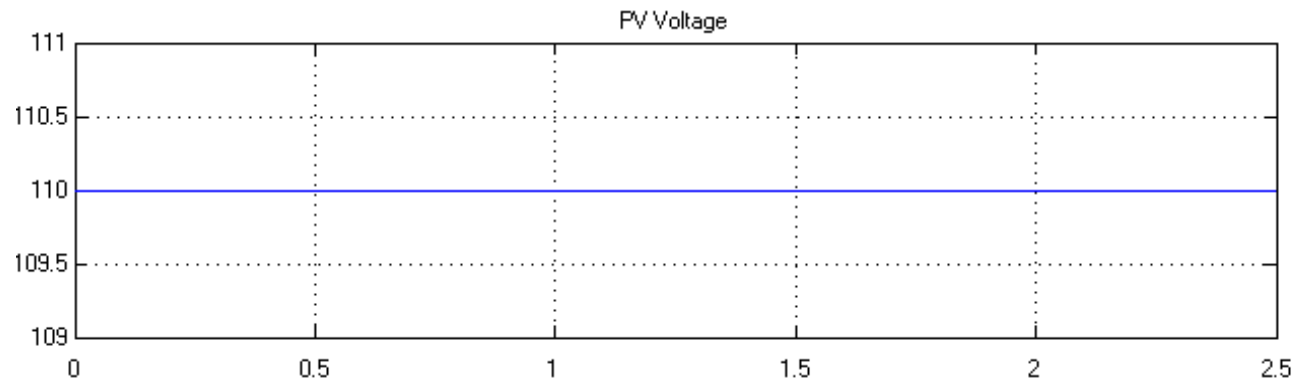

Figure 4. PV Voltage waveform

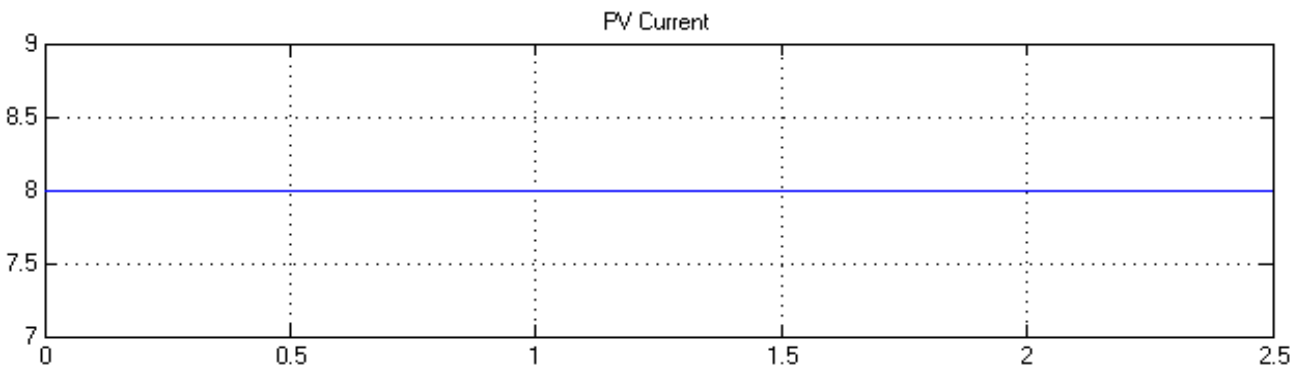

Figure 5. PV current waveform

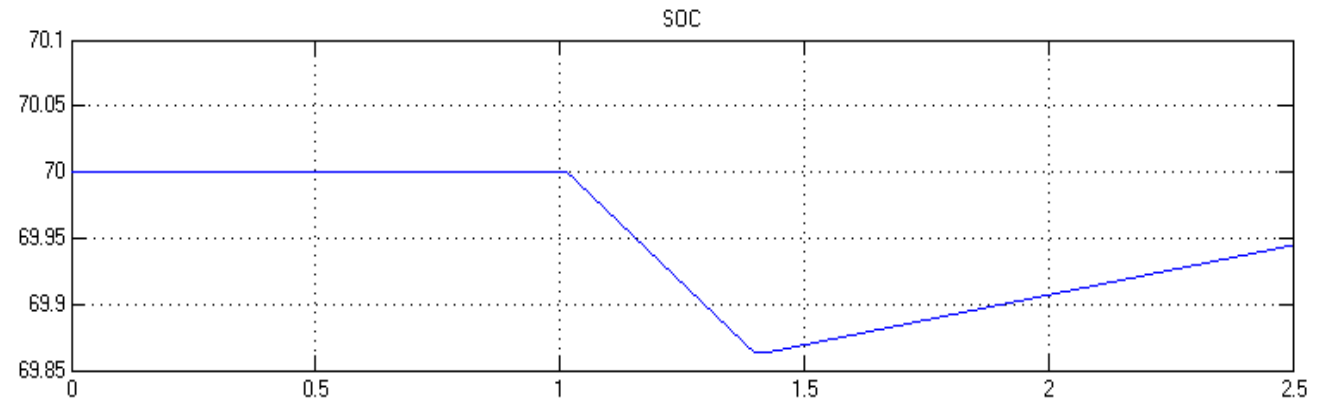

Figure 6. State of charge condition in battery

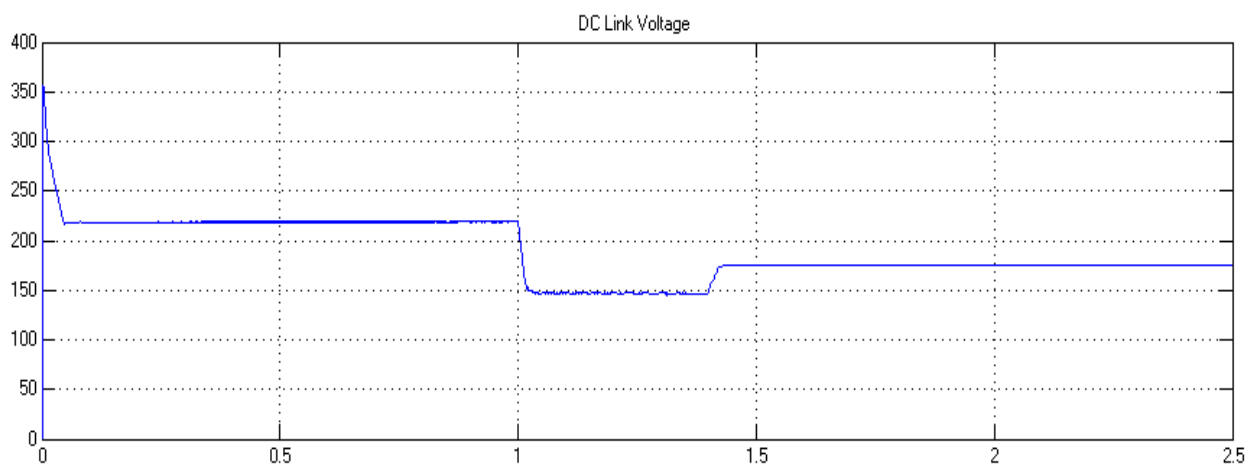

Figure 7. DC Link voltage 


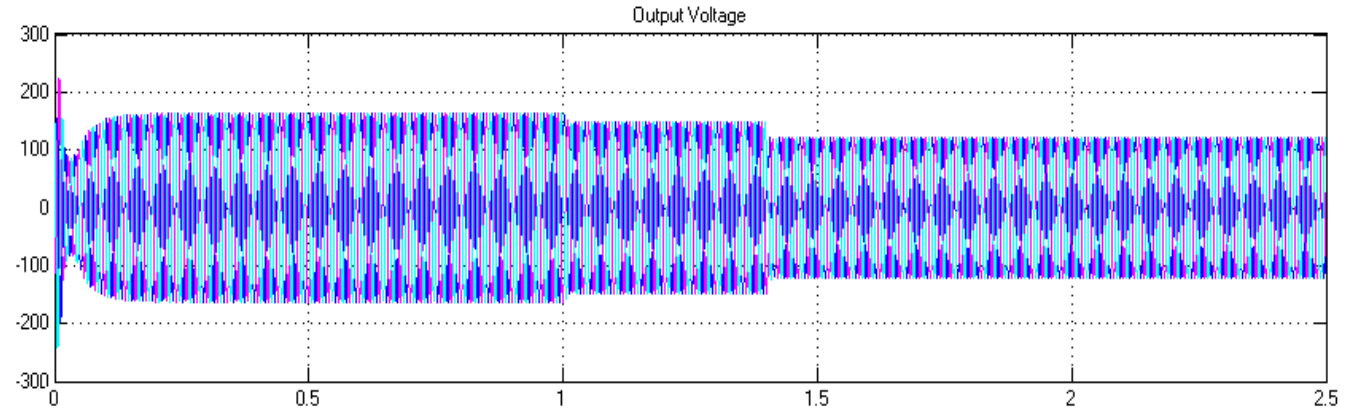

Figure 8. Output voltage waveform of bidirectional inverter

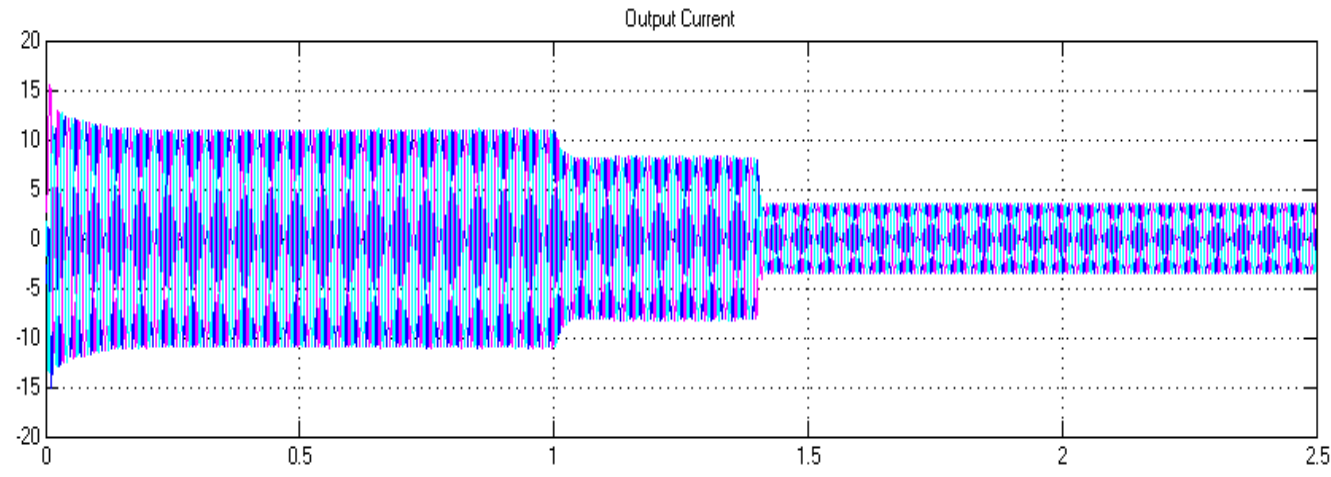

Figure 9. Output current waveform of bidirectional Inverter

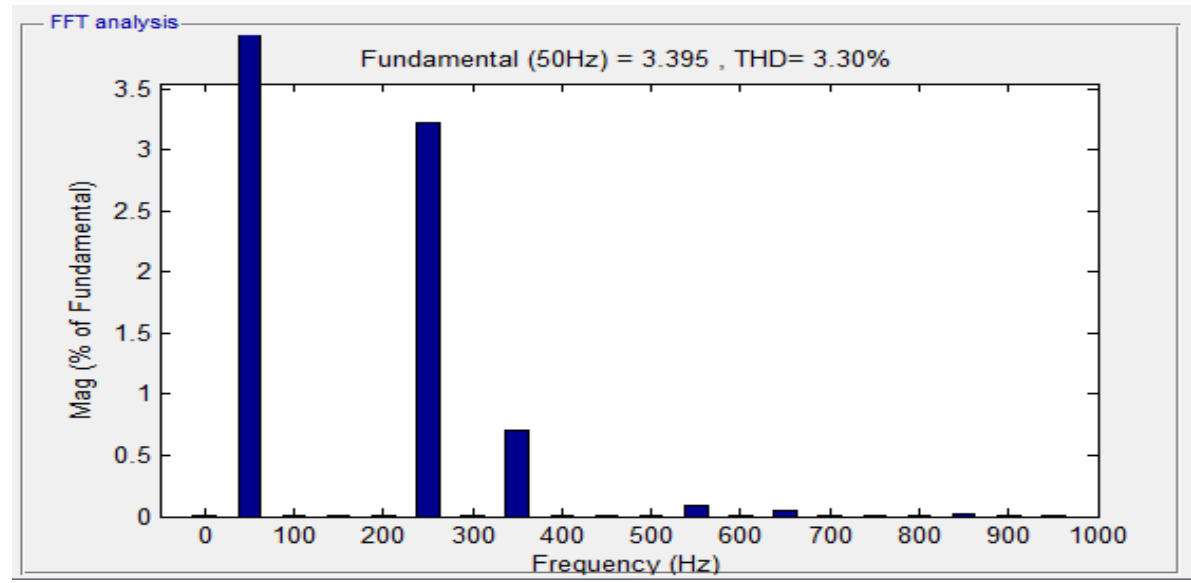

Figure 10. Total Harmonic Distortion

\section{CONCLUSION}

The three-phase bidirectional inverter based on model predictive control has been designed and implemented. The inverter fed grid-connected system has used to control the power flow between PV and grid. In forwarding direction, the bidirectional converter works have a boost converter, and output is fed into the bidirectional inverter utilize the model predictive control to regulate the power and enhance the efficiency of the system. The grid connected system For the utility grid interface bidirectional application, the photovoltaic with battery energy storage system is essential not only for controlling and managing the energy demand across utility grid in forward conduction, In the reverse direction, a battery is charged while absent of photovoltaic unit in order to demand of power in the different area. The efficiency and power flow control are regulated in grid-based bidirectional inverter fed PV system. 


\section{REFERENCES}

[1] Sayed et al., "PWM Switching Technique for Three-Phase Bidirectional Grid-Tie DC-AC-AC Converter with HighFrequency Isolation," IEEE Transactions on Power Electronics, vol. 33, no. 1, pp. 845-858, 2018.

[2] Xuewei et al., "Current-fed soft-switching push-pull front-end converter-based bidirectional inverter for the residential photovoltaic power system," IEEE Transactions on Power Electronics, vol. 29, no. 11, pp. 6041-6051, 2014

[3] Waltrich et al., "Three-phase bidirectional dc/ac converter using a six-leg inverter connected to a direct ac/ac converter," IET Power Electronics, vol. 8, no. 11, pp. 2214-2222, 2015.

[4] Kouro et al., "Grid-connected photovoltaic systems: An overview of recent research and emerging PV converter technology," IEEE Industrial Electronics Magazine, vol. 9, no. 1, pp. 47-61, 2015.

[5] Jaber Fallah Ardashiret al., "A Single-Phase Transformerless Inverter with Charge Pump Circuit Concept for GridTied PV Applications," Industrial Electronics IEEE Transactions, vol. 64, pp. 5403-5415, 2017.

[6] Lo et al., "Bidirectional Single-Stage Grid-Connected Inverter for a Battery Energy Storage System," IEEE Transactions on Industrial Electronics, vol. 64, no. 6, pp. 4581-4590, 2017.

[7] Wu et al., "DC-bus voltage control with a three-phase bidirectional inverter for DC distribution systems," IEEE Transactions on Power Electronics, vol. 28, no. 4, pp. 1890-1899, 2013.

[8] Yang et al., "Design and analysis of a grid-connected photovoltaic power system," IEEE transactions on power electronics, vol. 25, no. 4, pp. 992-1000, 2010.

[9] Wu et al., "Integration and operation of a single-phase bidirectional inverter with two buck/boost MPPTs for DCdistribution applications," IEEE Transactions on Power Electronics, vol. 28, no. 11, pp. 5098-5106, 2013.

[10] Jang et al., "A minimum power-processing-stage fuel-cell energy system based on a boost-inverter with bidirectional backup battery storage." IEEE Transactions on Power Electronics, vol. 26, no. 5, pp. 1568-1577, 2011.

[11] $\mathrm{Wu}$ et al., "Two-phase modulated digital control for the three-phase bidirectional inverter with wide inductance variation," IEEE Transactions on Power Electronics, vol. 28, no. 4, pp. 1598-1607, 2013.

[12] Rajakaruna et al., "Design and control of a bidirectional Z-source inverter," In Power Engineering Conference, 2009. AUPEC 2009. Australasian Universities, pp. 1-6. IEEE, 2009.

[13] Kwon et al., "Bidirectional Grid-Connected Single-Power-Conversion Converter with Low-Input Battery Voltage," IEEE Transactions on Industrial Electronics, vol. 65, no. 4, pp. 3136-3144, 2018.

[14] Peng et al., "A new ZVS bidirectional DC-DC converter for fuel cell and battery application." IEEE Transactions on power electronics, vol. 19, no. 1, pp. 54-65, 2004.

[15] Chin et al., "An Accurate and Fast Computational Algorithm for the Two-diode Model of PV Module Based on a Hybrid Method," IEEE Transactions on Industrial Electronics, vol. 64, no. 8, pp. 6212-6222, 2017.

[16] A. Rahnamaei et al., "A Novel Grid Connected Photovoltaic System," Bulletin of Electrical Engineering and Informatics, vol. 5, pp. 133-143, 2017.

[17] V. Vasudevan and K. Balaji, "Performance of Cuk-KY Converter Fed Multilevel Inverter for Hybrid Sources," Indonesian Journal of Electrical Engineering and Computer Science, vol. 10, no. 2, pp. 2018.

[18] R. Balamurugan and R. Nithya, "FC/PV Fed SAF with Fuzzy Logic Control for Power Quality Enhancement," International Journal of Power Electronics and Drive Systems, vol. 5, no. 4 pp. 470-476, 2015. 